\title{
Global mapping of interventions to improve the quality of life of patients with cardiovascular diseases during 1990-2018
}

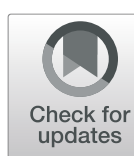

\author{
Bach Xuan Tran ${ }^{1,2^{*}} \mathbb{D}$, Son Nghiem³ ${ }^{3}$ Clifford Afoakwah ${ }^{3}$, Giang Hai Ha ${ }^{4}$, Linh Phuong Doan ${ }^{5}$, \\ Thao Phuong Nguyen ${ }^{6}$, Tuan Thanh Le ${ }^{7}$, Carl A. Latkin², Cyrus S. H. Ho ${ }^{8}$ and Roger C. M. Ho ${ }^{6,9,10}$
}

\begin{abstract}
Background: Cardiovascular diseases (CVDs) have been the global health problems that cause a substantial burden for the patients and the society. Assessing the Quality of Life (QOL) of CVD patients is critical in the effectiveness evaluation of CVD treatments as well as in determining potential areas for enhancing health outcomes. Through the adoption of a combination of bibliometric approach and content analysis, publications trend and the common topics regarding interventions to improve QOL of CVD patients were searched and characterized to inform priority setting and policy development.
\end{abstract}

Methods: Bibliographic data of publications published from 1990 to 2018 on interventions to improve QOL of CVD patients were retrieved from Web of Science. Network graphs illustrating the terms co-occurrence clusters were created by VOSviewer software. Latent Dirichlet Allocation approach was adopted to classify papers into major research topics.

Results: A total of 6457 papers was analyzed. We found a substantial increase in the number of publications, citations, and the number of download times of papers in the last 5 years. There has been a rise in the number of papers related to intervention to increase quality of life among patients with CVD during 1990-2018. Conventional therapies (surgery and medication), and psychological, behavioral interventions were common research topics. Meanwhile, the number of papers evaluating economic effectiveness has not been as high as that of other topics.

Conclusions: The research areas among the scientific studies emphasized the importance of interdisciplinary and intersectoral approaches in both evaluation and intervention. Future research should be a focus on economic evaluation of intervention as well as interventions to reduce mental issues among people with CVD.

Keywords: Scientometrics, Content analysis, Text mining, Interventions, CVD, QOL, Global, Mapping

\footnotetext{
* Correspondence: bach.ipmph@gmail.com

'Department of Health Economics, Institute for Preventive Medicine and

Public Health, Hanoi Medical University, No.1 Ton That Tung street, Dong Da, Hanoi, Vietnam

${ }^{2}$ Bloomberg School of Public Health, Johns Hopkins University, Baltimore,

MD, USA

Full list of author information is available at the end of the article
}

(C) The Author(s). 2020 Open Access This article is licensed under a Creative Commons Attribution 4.0 International License, which permits use, sharing, adaptation, distribution and reproduction in any medium or format, as long as you give appropriate credit to the original author(s) and the source, provide a link to the Creative Commons licence, and indicate if changes were made. The images or other third party material in this article are included in the article's Creative Commons licence, unless indicated otherwise in a credit line to the material. If material is not included in the article's Creative Commons licence and your intended use is not permitted by statutory regulation or exceeds the permitted use, you will need to obtain permission directly from the copyright holder. To view a copy of this licence, visit http://creativecommons.org/licenses/by/4.0/. The Creative Commons Public Domain Dedication waiver (http://creativecommons.org/publicdomain/zero/1.0/) applies to the data made available in this article, unless otherwise stated in a credit line to the data. 


\section{Background}

Cardiovascular diseases (CVDs) have been the global health problem with rising prevalence, incidence, and death rates. In 2017, 31.8\% (17.79 million cases) of global deaths were attributed to CVDs, plus nearly 336 million disability-adjusted life-years (DALY) [1]. Ischemic heart disease (IHD) and stroke account for the highest standardized death rate among CVD causes [2]. Episodes of CVDs have complex, long term impacts on the life of patients, which is far beyond survivorship, since their consequences cause impairments in physical and cognitive functioning, which, in turn, limit the daily activities and social interactions of the survivors [3-7].

Achieving good quality of life (QOL), therefore, is crucial to patients suffering from heart and stroke diseases $[3,8]$. According to the definition of World Health Organization on QOL, QOL is "affected in a complex way by the person's physical health, psychological state, personal beliefs, social relationships and their relationship to salient features of their environment" [9]. QOL can be considered as one of the most important outcomes in healthcare, particularly among patients with CVDs [10]. Deterioration of QOL among CVD patients is positively correlated with higher rates of hospital readmission and fatality [11, 12]. Hence, assessing the QOL of CVD patients is critical when evaluating the effectiveness of CVD treatments and determining which aspects should be improved.

There is a remarkable growth in the body of literature regarding manners to improve the QOL of people with heart and stroke diseases. These implications range from healthier lifestyle encouragement [13] to the incorporation of mental health treatments into routine CVDs management [6]. Moreover, some initiatives have been implemented comprising: adoption of collaborative care models [14]; support and counseling of CVD specialists in the primary care setting to people at-risk of CVDs [15]; or adoption of surgical procedures, for instance, coronary artery bypass graft surgery (CABG) instead of percutaneous coronary intervention (PCI) [16].

Several systematic reviews worked on interventions that could improve the QOL of people with heart and stroke diseases. For example, life-style interventions at the workplace could decrease the risk of CVD [17], or communitybased nursing interventions increase the outcome of treatment for people with CVD [18]. Besides, Widmer et al. confirmed the effectiveness of digital health interventions for the prevention of cardiovascular disease [19]. Despite the abundance of documents on the QOL and interventions targeting people with heart and stroke diseases, there is a lack of publications offering a 'big picture' of the interaction between interventions and QOL among CVD patients. This limits the ability of healthcare providers and policymakers to identify pathways to efficiently allocate scarce resources in CVD treatment.
The bibliometric approach has been proposed to be a potential solution given the capacity to provide a comprehensive and holistic investigation of the literature. By combining bibliometric approach and content analysis, we aimed at providing an interdisciplinary insights into research areas as well as characterizing the most common topics regarding interventions to improve QOL of CVD patients. Our findings can inform priority setting and policy development towards sustainable efforts of enhancing the lives of people with these conditions.

\section{Methods}

Search strategy, keywords, data download and extraction

The published works regarding the QOL of CVD patients were downloaded from the Web of Science (WOS). For bibliometric analysis, the WOS is superior to Scopus or Medline/Pubmed because it: 1) allows to extract a large number of with full information (e.g titles, author names, total citation, total download times); 2) covers citation of scientific publications since 1900; and 3) comprises high impact scientific journals worldwide [20, 21]. Data were collected in March 2019; thus, we excluded the publications from 1st January 2019 onwards. The analysis focused on English articles and reviews, therefore, other document types such as letter to editors, or conference abstracts in any other languages were excluded. Two steps of the search strategy were performed as follow:

- Step 1: The terms "Quality of life", and "well-being" were used to extract scientific research mentioning Quality of life on TS research in WOS (title, abstract, keywords, and topic) (see Additional file 1). Data were downloaded separately by two researchers and verified by a senior researcher. Any inconsistency between the data downloaded by the two researchers was solved by discussion and the data were re-downloaded when necessary. Papers which were 1) not articles and reviews; 2) not published in English; 3) written by anonymous authors. Final set of data was converted into txt format and transferred into STATA version 14.0 (STATACorp., Texas, USA) for further extraction and analysis.

- Step 2: A set of keywords related to CVDs was built, which based on the definition of World Health Organization (WHO), ("Coronary heart disease" OR "Heart failure" OR "Rheumatic Heart Disease" OR "Cerebrovascular disease") [22], MeSH terms ("Cardiac arrhythmias" OR "Carcinoid heart disease" OR "Cardiac conduction system disease" OR "High cardiac output" OR "Low cardiac output" OR "Cardiomegaly" OR "Endocarditis" OR "heart aneurysm" OR "Heart arrest" OR "Congenital heart defects" OR "Heart neoplasms" OR "Heart rupture" OR "Heart attack" OR "Heart valve disease" OR 
Table 1 Summary of analytical techniques for each data types

\begin{tabular}{llll}
\hline Type of data & Unit of analysis & Analytical methods & Presentations of results \\
\hline Keywords & Words & Frequency of co-occurrence & 1) Map of authors' keywords \\
Abstracts & Papers & Latent Dirichlet Allocation & 2) Ten classifications of research topics \\
WoS classification of research areas & WoS research areas & Frequency of co-occurrence & 3) Dendrogram of research disciplines (WoS classification)
\end{tabular}

"Myocardial ischemia" OR "Myocardial Ischemia" OR "Pericardial Effusion" OR "Pericarditis" OR "Ventricular Dysfunction" OR "Ventricular Outflow Obstruction" OR "Cardiovascular abnormalities" OR "Vascular malformations" OR "Cardiovascular infections") [23], some systematic reviews (such as ("Ischemic heart disease" OR "Heart attack" OR "Stroke" OR "ischemic stroke" OR "Hemorrhagic stroke" OR "brain attack") [24, 25]. Then, we used the terms "intervention" " or "trial" to extract the papers regarding the intervention of this health problem (see Additional file 2).

\section{Data analysis}

First, basic characteristics of publications were described, which included 1) years of publication; 2) the number of papers per year; 3) total citations of each year up to 2018 (from 1990 to 2018); 4) a total of download times (total

Table 2 General characteristics of publications

\begin{tabular}{|c|c|c|c|c|c|c|c|}
\hline $\begin{array}{l}\text { Year } \\
\text { published }\end{array}$ & $\begin{array}{l}\text { Total number of } \\
\text { papers }\end{array}$ & $\begin{array}{l}\text { Total } \\
\text { citations }\end{array}$ & $\begin{array}{l}\text { Mean cite rate } \\
\text { per year }\end{array}$ & $\begin{array}{l}\text { Total usage last } 6 \\
\text { month }\end{array}$ & $\begin{array}{l}\text { Total usage last } 5 \\
\text { years }\end{array}$ & $\begin{array}{l}\text { Mean use rate last } 6 \\
\text { month }\end{array}$ & $\begin{array}{l}\text { Mean use rate last } \\
5 \text { year }\end{array}$ \\
\hline 2018 & 700 & 737 & 1.05 & 1953 & 3045 & 2.79 & 0.87 \\
\hline 2017 & 659 & 3666 & 2.78 & 989 & 4769 & 1.50 & 1.45 \\
\hline 2016 & 578 & 6871 & 3.96 & 697 & 6667 & 1.21 & 2.31 \\
\hline 2015 & 552 & 8684 & 3.93 & 533 & 6975 & 0.97 & 2.53 \\
\hline 2014 & 464 & 9118 & 3.93 & 343 & 5737 & 0.74 & 2.47 \\
\hline 2013 & 463 & 12,830 & 4.62 & 314 & 7335 & 0.68 & 3.17 \\
\hline 2012 & 431 & 13,162 & 4.36 & 273 & 5818 & 0.63 & 2.70 \\
\hline 2011 & 365 & 12,192 & 4.18 & 214 & 4187 & 0.59 & 2.29 \\
\hline 2010 & 309 & 12,414 & 4.46 & 209 & 3095 & 0.68 & 2.00 \\
\hline 2009 & 269 & 12,780 & 4.75 & 152 & 2357 & 0.57 & 1.75 \\
\hline 2008 & 238 & 9916 & 3.79 & 125 & 1963 & 0.53 & 1.65 \\
\hline 2007 & 241 & 14,878 & 5.14 & 109 & 1883 & 0.45 & 1.56 \\
\hline 2006 & 184 & 12,221 & 5.11 & 71 & 1328 & 0.39 & 1.44 \\
\hline 2005 & 182 & 14,436 & 5.67 & 64 & 1361 & 0.35 & 1.50 \\
\hline 2004 & 159 & 15,142 & 6.35 & 118 & 1958 & 0.74 & 2.46 \\
\hline 2003 & 119 & 9924 & 5.21 & 47 & 737 & 0.39 & 1.24 \\
\hline 2002 & 103 & 14,757 & 8.43 & 48 & 958 & 0.47 & 1.86 \\
\hline 2001 & 72 & 7578 & 5.85 & 30 & 493 & 0.42 & 1.37 \\
\hline 2000 & 77 & 7457 & 5.10 & 17 & 397 & 0.22 & 1.03 \\
\hline 1999 & 66 & 6225 & 4.72 & 24 & 421 & 0.36 & 1.28 \\
\hline 1998 & 58 & 3524 & 2.89 & 14 & 221 & 0.24 & 0.76 \\
\hline 1997 & 35 & 2735 & 3.55 & 12 & 229 & 0.34 & 1.31 \\
\hline 1996 & 36 & 2995 & 3.62 & 6 & 104 & 0.17 & 0.58 \\
\hline 1995 & 23 & 3295 & 5.97 & 3 & 147 & 0.13 & 1.28 \\
\hline 1994 & 23 & 1451 & 2.52 & 5 & 70 & 0.22 & 0.61 \\
\hline 1993 & 26 & 842 & 1.25 & 6 & 29 & 0.23 & 0.22 \\
\hline 1992 & 13 & 599 & 1.71 & 0 & 31 & 0.00 & 0.48 \\
\hline 1991 & 11 & 2880 & 9.35 & 6 & 71 & 0.55 & 1.29 \\
\hline 1990 & 1 & 40 & 1.38 & 0 & 1 & 0.00 & 0.20 \\
\hline
\end{tabular}


usage) and average download times per year (mean usage per year) in the last 6 months; and 5) total of download times (total usage) and the average number of citation per year (mean citation rate per year) in the last 5 years. A network graph showing the cooccurrence of authors' keywords was generated by the VOSviewer software tool (https://www.vosviewer.com/ ). The Latent Dirichlet Allocation (LDA), a generative statistical model, was used for classifying publications into topics [26-30]. The LDA approach was selected because of its ability to group and explain trends and patterns in text content. The techniques used for each type of type are presented in Table 1.

\section{Results}

Number of published items and publication trend

Table 2 reveals the characteristics of selected publications. The first paper was published in 1990. Then, there was a gradual increase in the number of interventions to improve QOL of patients with stroke and heart diseases during 1990-2018, resulting in a total of 6457 papers. Besides, the total number of download times (total usage), and the average number of download times (the mean use rate) in the last 5 years of papers published in 2013 were the highest compared with other years. Meanwhile, the total usage and the mean use rate last 6 months of the year 2019 were the highest figures

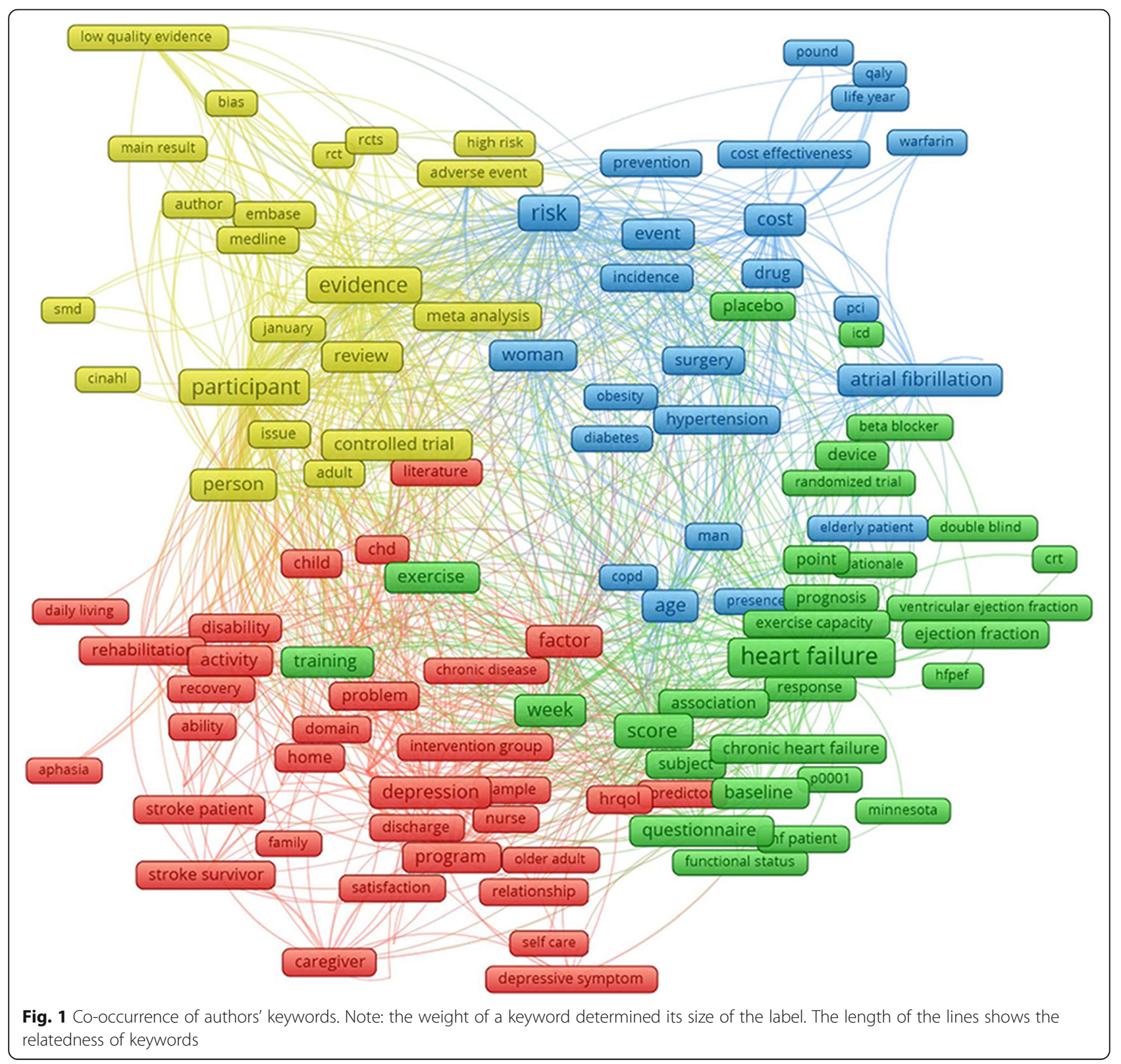


Table 3 Most cited papers

\begin{tabular}{ll} 
Title \\
\hline 1 Cardiac resynchronization in chronic heart failure \\
2 Prevention of stroke by antihypertensive drug-treatment in older persons with isolated systolic \\
hypertension - final results of the systolic hypertension in the elderly program (shep)
\end{tabular}

3 A randomized trial of the angiotensin-receptor blocker valsartan in chronic heart failure

4 Advanced Heart Failure Treated with Continuous-Flow Left Ventricular Assist Device

Journal Cite Year Cite

New England journal of

rate

medicine

JAMA-journal of the American medical association

New England journal of

$18872001 \quad 105$ medicine

New England journal of

5 A multidisciplinary intervention to prevent the readmission of elderly patients with congestiveheart-failure

medicine

New England journal of medicine

6 Exercise-based rehabilitation for patients with coronary heart disease: Systematic review and meta-analysis of randomized controlled trials

American journal of

medicine

1268200485

7 Evidence suggesting that a chronic disease self-management program can improve health status while reducing hospitalization - A randomized trial

8 Lifetime risk for development of atrial fibrillation - The Framingham Heart Study

Medical care

189199959

Circulation

1100200473

9 Combined cardiac resynchronization and implantable cardioversion defibrillation in advanced chronic heart failure - The MIRACLE ICD Trial

JAMA-journal of the American medical association

10 Effect of constraint-induced movement therapy on upper extremity function 3 to 9 months after stroke - The EXCITE randomized clinical trial

JAMA-journal of the American medical association

11 Treatment of heart failure guided by plasma aminoterminal brain natriuretic peptide (N-BNP) concentrations

Lancet

12 Early decompressive surgery in malignant infarction of the middle cerebral artery: a pooled analysis of three randomised controlled trials

Lancet neurology

13 Effects of controlled-release metoprolol on total mortality, hospitalizations, and well-being in patients with heart failure - The metoprolol CR/XL randomized intervention trial in congestive heart failure (MERIT-HF)

JAMA-journal of the American medical

14 Collaborative Care for Patients with Depression and Chronic Illnesses. association

New England journal of medicine

15 Evaluation study of congestive heart failure and pulmonary artery catheterization effectiveness The ESCAPE trial

JAMA-journal of the American medical

16 Spironolactone for Heart Failure with Preserved Ejection Fraction association

New England journal of medicine

17 Continuous positive airway pressure for central sleep apnea and heart failure

New England journal of medicine

18 Long-term benefits of biventricular pacing in congestive heart failure: Results from the multisite stimulation in cardiomyopathy (MUSTIC) study

Journal of the American

606200236 college of cardiology

19 Exercise training meta-analysis of trials in patients with chronic heart failure (extramatch)

BMJ-British medical journal

New England journal of

20 Catheter ablation for atrial fibrillation in congestive heart failure medicine

21 Does increased access to primary care reduce hospital readmissions?

New England journal of $\quad 504 \quad 199622$ medicine

JAMA-journal of the American medical association

23 Effect of Phosphodiesterase-5 Inhibition on Exercise Capacity and Clinical Status in Heart Failure With Preserved Ejection Fraction A Randomized Clinical Trial

JAMA-journal of the American medical association

24 Menopausal Hormone Therapy and Health Outcomes During the Intervention and Extended Poststopping Phases of the Women's Health Initiative Randomized Trials 
Table 3 Most cited papers (Continued)

\begin{tabular}{|c|c|c|c|c|c|}
\hline & Title & Journal & Cite & Year & $\begin{array}{l}\text { Cite } \\
\text { rate }\end{array}$ \\
\hline 25 & $\begin{array}{l}\text { Anger, anxiety, and depression as risk factors for cardiovascular disease: The problems and } \\
\text { implications of overlapping affective dispositions }\end{array}$ & Psychological bulletin & 460 & 2005 & 33 \\
\hline 26 & $\begin{array}{l}\text { Cardiac resynchronization therapy for the treatment of heart failure in patients with } \\
\text { intraventricular conduction delay and malignant ventricular tachyarrhythmias }\end{array}$ & $\begin{array}{l}\text { Journal of the American } \\
\text { college of cardiology }\end{array}$ & 448 & 2003 & 28 \\
\hline 27 & $\begin{array}{l}\text { The association of depression and anxiety with medical symptom burden in patients with } \\
\text { chronic medical illness }\end{array}$ & General hospital psychiatry & 441 & 2007 & 37 \\
\hline 28 & $\begin{array}{l}\text { Combined intravenous and intra-arterial r-TPA versus intra-arterial therapy of acute ischemic } \\
\text { stroke - Emergency management of stroke (EMS) bridging trial }\end{array}$ & Stroke & 441 & 1999 & 22 \\
\hline 29 & $\begin{array}{l}\text { Double-blind, placebo-controlled study of the effects of carvedilol in patients with moderate to } \\
\text { severe heart failure - The PRECISE trial }\end{array}$ & Circulation & 435 & 1996 & 19 \\
\hline 30 & Sex differences in stroke: epidemiology, clinical presentation, medical care, and outcomes & Lancet neurology & 428 & 2008 & 39 \\
\hline 31 & $\begin{array}{l}\text { A dose-dependent increase in mortality with vesnarinone among patients with severe heart } \\
\text { failure }\end{array}$ & $\begin{array}{l}\text { New England journal of } \\
\text { medicine }\end{array}$ & 425 & 1998 & 20 \\
\hline 32 & $\begin{array}{l}\text { Surgical decompression for space-occupying cerebral infarction (the Hemicraniectomy After } \\
\text { Middle Cerebral Artery infarction with Life-threatening Edema Trial [HAMLET]): a multi-centre, } \\
\text { open, randomised trial }\end{array}$ & Lancet neurology & 424 & 2009 & 42 \\
\hline 33 & Statins for the primary prevention of cardiovascular disease & $\begin{array}{l}\text { Cochrane database of } \\
\text { systematic reviews }\end{array}$ & 423 & 2013 & 71 \\
\hline 34 & $\begin{array}{l}\text { Effects of a multidisciplinary, home-based intervention on unplanned readmissions and survival } \\
\text { among patients with chronic congestive heart failure: a randomised controlled study }\end{array}$ & Lancet & 407 & 1999 & 20 \\
\hline 35 & Beraprost therapy for pulmonary arterial hypertension & $\begin{array}{l}\text { Journal of the American } \\
\text { college of cardiology }\end{array}$ & 404 & 2003 & 25 \\
\hline 36 & Effect of Cinacalcet on Cardiovascular Disease in Patients Undergoing Dialysis & $\begin{array}{l}\text { New England journal of } \\
\text { medicine }\end{array}$ & 403 & 2012 & 58 \\
\hline 37 & $\begin{array}{l}\text { A randomized controlled trial of epoprostenol therapy for severe congestive heart failure: The } \\
\text { Flolan International Randomized Survival Trial (FIRST) }\end{array}$ & American heart journal & 400 & 1997 & 18 \\
\hline
\end{tabular}

compared with that of other years, which indicated the short-term interest of readers,

The scope of studies was explored by using authors' keywords, which was automatically mapped by the VOSviewer software tool. Figure 1 indicates four major clusters emerged from 164 most common keywords which appeared at least 200 times. Cluster 1 (red) refers to the quality of life, rehabilitation, and mental health illness of stroke patients. Cluster 2 (green) focuses on the daily exercise of patients with heart failure. Cluster 3 (yellow) includes types of analysis applied to identify the QOL among patients with heart diseases and stroke. Cluster 4 (blue) illustrates the risk factors, prevention, and costeffectiveness of interventions for CVD.

Table 3 shows the most cited papers which had at least 400 citations. The title and abstract of each paper were reviewed by the research team and assigned to corresponding topics. Three major topics have been emerged encompassing: 1) Treatment of stroke or heart diseases (24/39 papers); 2) Preventions of stroke or heart diseases (8/39 papers), and 3) Others (systematic review and meta-analysis) (5/39 papers).

The LDA was utilized to model the research topics based on texts in the abstracts and a total of ten major research topics was constructed (Table 4). Each topic was labeled by reviewing titles and abstracts of most cited papers within each group. Ten topics were divided into the following categories: 1) conventional therapies: topic 5 , and topic $7 ; 2$ ) other therapies: topic 2 , topic 3 , topic 4 , topic 6 , topic 8 , topic 9 , and topic 10 . Figure 2 illustrates that recently, researchers have paid greater attention to two research topics focusing on biomedical therapies (topic 1), which are now under research and trial, as well as psychological and behavioral therapies for people with heart diseases (Topic 2).

Figure 3 presents the clusters of research areas in the interventions aiming to improve QOL of CVD patients. The horizontal axis shows the distance between research areas while the vertical axis shows the research areas based on WOS categories. The research areas in these interventions could be divided into three categories 1) Cardiovascular System; 2) Prevention, Treatment (Surgery, Internal Medicine, Pharmacy and Rehabilitation); 3) Health Policy and Economic evaluation. Overall, the dendrogram indicates that health services and economics studies have not been well studied. Also, holistic (e.g., system) factors and frontline interactions with patients (e.g., nursing) seem to have influential effects on QOL of CVD patients. 
Table 4 Ten research topics classified by LDA

\begin{tabular}{|c|c|c|c|}
\hline Rank by the highest volume last 5 years & Research topics & $\mathrm{N}$ & Percent \\
\hline Topic 1 & Gene, Cell and Biomedical Therapies for heart diseases & 799 & $14.1 \%$ \\
\hline Topic 2 & Psychological, Behavioral and Social impairments of patients with heart diseases & 794 & $14.0 \%$ \\
\hline Topic 3 & Health Education, Motivation and Behavioral Interventions & 670 & $11.8 \%$ \\
\hline Topic 4 & Technology-based, Robot-assisted Interventions on patients with Stroke & 563 & $9.9 \%$ \\
\hline Topic 5 & Clinical, drug therapies for heart failure & 751 & $13.2 \%$ \\
\hline Topic 6 & Traditional and Alternative Medicine for heart diseases & 426 & $7.5 \%$ \\
\hline Topic 7 & Cardiac Surgeries and Interventions & 506 & $8.9 \%$ \\
\hline Topic 8 & Economic Evaluation of Interventions on Patients with heart diseases and stroke & 457 & $8.1 \%$ \\
\hline Topic 9 & Physical Activity and Exercise training for patients with heart failure & 315 & $5.5 \%$ \\
\hline Topic 10 & Effectiveness of hormone replacement therapy on heart diseases & 396 & $7.0 \%$ \\
\hline
\end{tabular}

\section{Discussion}

In this study, a total of 6457 papers was analyzed to identify the global trend and the development of research landscapes in the intervention to improve QOL of CVD patients from 1990 to 2018. The number of papers increased gradually since 2002 and reached a peak in the year of 2018. By applying text mining technique based on LDA, the interdisciplinary research topics and research areas were examined in detail. The most common topics were conventional treatment (surgery and medication), and psychological, behavioral interventions.

Our study proposed a novel approach for analyzing literature that overcomes the limitations of current systematic review/meta-analysis. Indeed, the traditional systematic review and meta-analysis cannot efficiently illustrate the research development trend as this method consumes time and human resources [31]. Meanwhile, scientometrics, when standing on its own, shows the productivity, collaborations among authors, organizations, or countries and cooccurrence of author keywords, however, the approach is unable to identify the research topics underlying the current literature [32]. By combining bibliometrics and text analysis, the study was able to explore the hidden patterns of information from the literature.

This study provides an overview of interdisciplinary research landscapes in the interventions to improve QOL

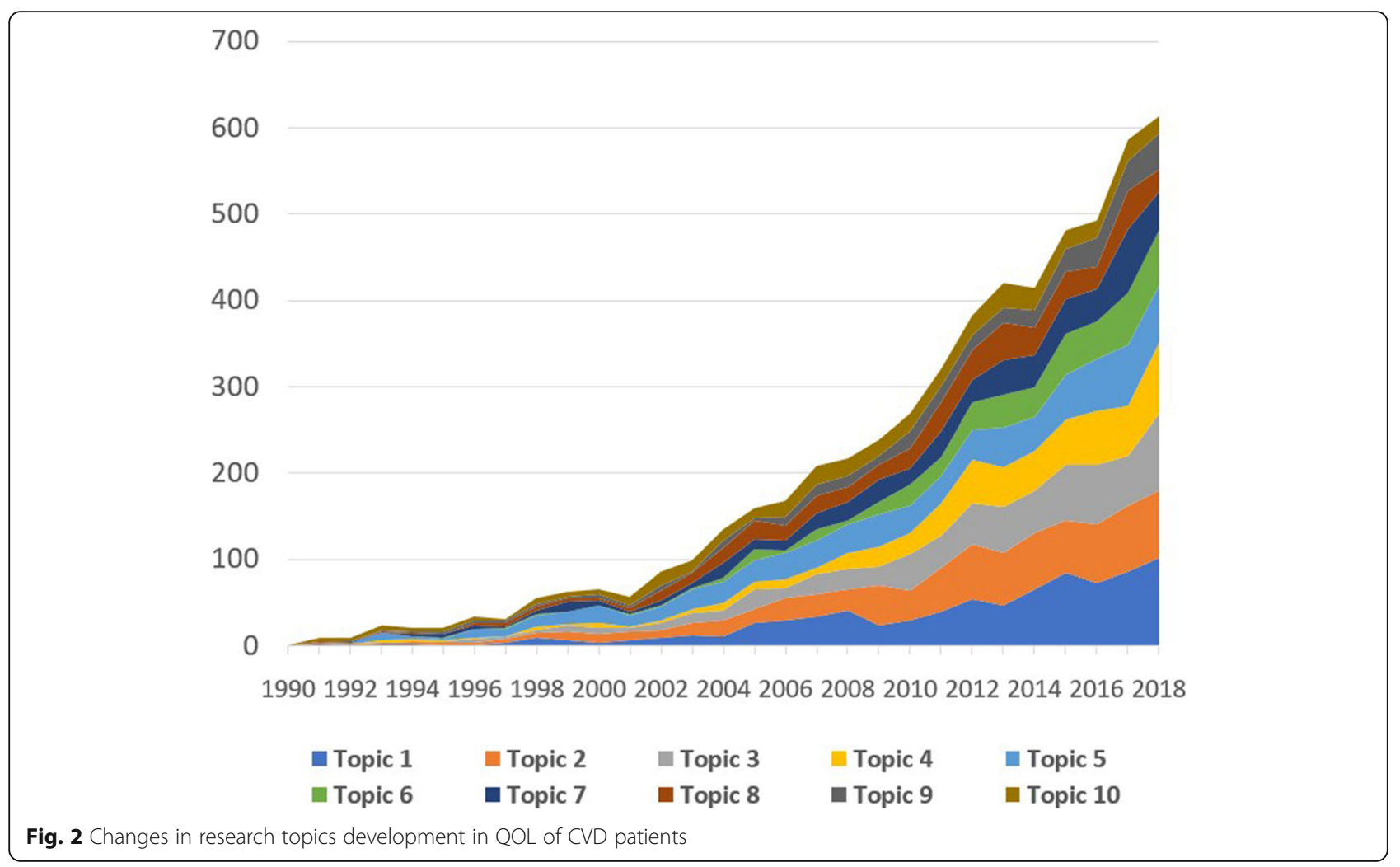




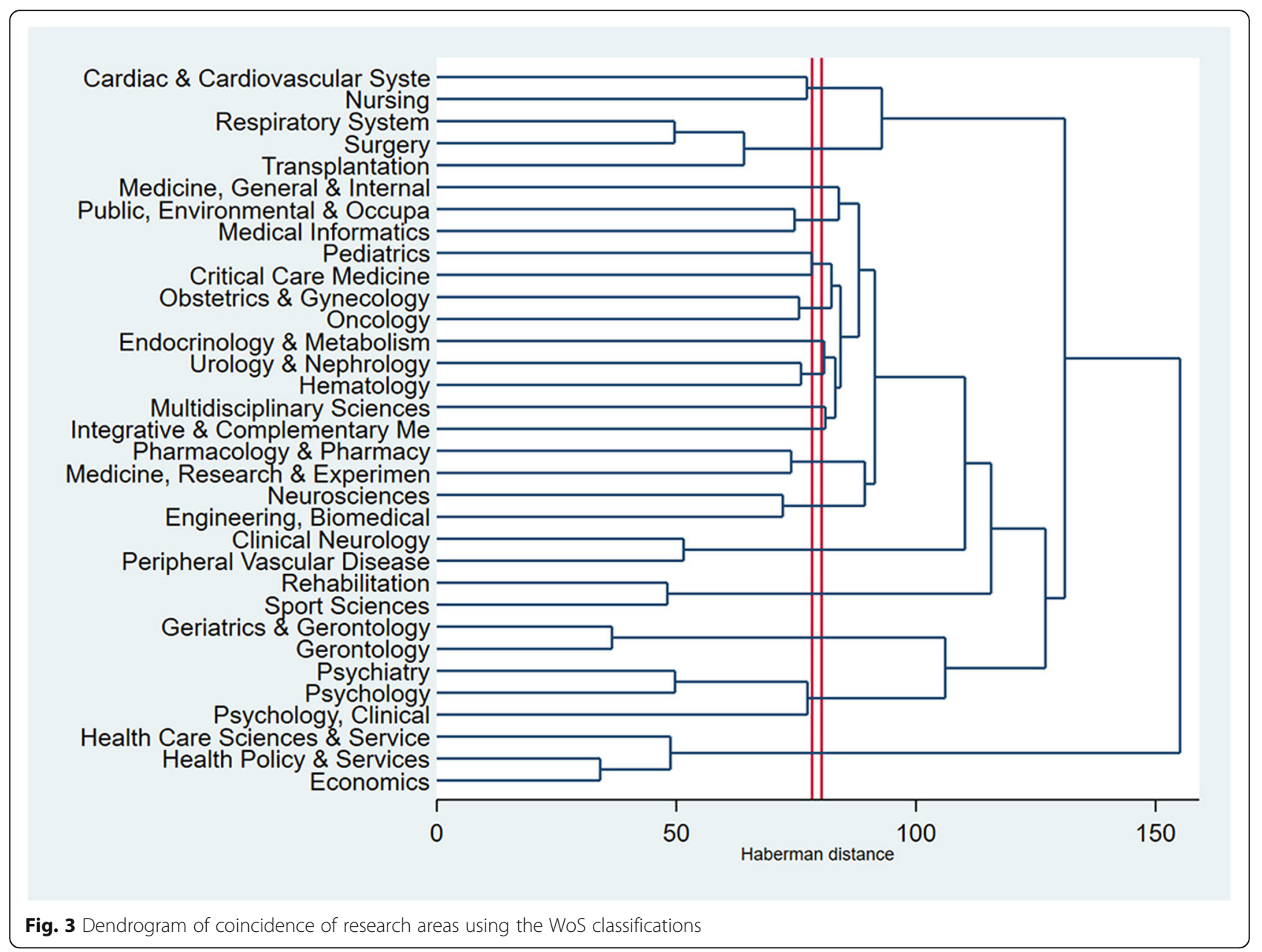

of CVD patients. The majority of interventions for CVDs were conventional therapies, such as surgery and medication, or psychological and behavioral interventions. Historically, the use of medications has been a primary method of CVD treatment [33], given the lower costs of drug treatment compared to hospitalization and effectiveness in relieving symptoms, which mainly aim to slow down the disease progression and improve patients' QoL [34]. The number of patients with end-stage heart diseases as well as the introduction of the heart-lung machine and cardiopulmonary bypass leads to the increase of surgical treatment and the number of papers mentioning this therapy, which was also confirmed by other studies [35]. Besides, several associated factors to CVDs, such as obesity, smoking, and sedentary lifestyle, have been proved in previous studies [36, 37], leading to a rise in the published works regarding interventions focusing in lifestyle changes to prevent the onset of CVD episode and elevate the patients' QOL. Notably, traditional and alternative medicine gained the concern of scientists in the last 5 years (20142018). This result was in the same line with previous studies [38, 39]. It might be explained that patients believed in these approaches to reduce side-effects of conventional therapy [39], yet, there has been a lack of data for the pattern use of alternative therapy for CVDs [38]. In addition, the development of technology has enabled the research of gene therapy or robot-assistant in CVD treatment [40]. However, gene therapy has shown modest success in clinical translation [41]. Meanwhile, robot-assistant has been tried and is being investigated for rehabilitation among patients after stroke [42, 43].

Findings of this study have provided several important implications for setting priority in research, designing interventions, and improving quality of care for CVD patients. Firstly, we call for interdisciplinary approaches, specifically, the integration of research areas, such as health services in providing medical care, and psychosocio-behavioral interventions at the individual, family, health facility, and community levels. Besides, more research should be focused on the economic aspects of interventions for CVD. Finally, there has been a lack of research on interventions to reduce mental problems (e.g., depression or stress) among people with CVD; hence, future research should focus on this phenomenon since 
mental issues were significant risk factors for CVD [44, 45].

Our study has several limitations. First, the choice of using WOS as the only database might limit the coverage of all possible publications in interventions to improve QoL of patients with CVD compared with Google Scholar [46], or Scopus [47]. However, a previous study recommended using WoS in the case of only one available database [48]. Second, only peer-reviewed publications in the English language were included, which might have resulted in a bias against non-English publications. Furthermore, only titles and abstracts were used for content analysis, which might not provide a deep insight intro research themes of the dataset. Hence, our findings should be interpreted with caution.

\section{Conclusion}

In conclusion, the number of scientific published works on the interventions to improve QOL among people with CVD has gradually increased from 1990 to 2018. The research areas in the field of the study emphasized the importance of interdisciplinary and inter-sectoral approaches in both evaluation and intervention. Conventional therapy (surgery and medication), and psychological and behavioral interventions were the common approach. Future research should focus on economic evaluation of intervention as well as interventions to reduce mental issues among people with CVD.

\section{Supplementary information}

Supplementary information accompanies this paper at https://doi.org/10. 1186/s12955-020-01507-9.

Additional file 1. Search query for "Quality of life" and "well-being".

Number of papers by countries as study settings

Additional file 2. Selection process

\section{Abbreviations}

CABG: Coronary Artery Bypass Graft Surgery; CVDs: Cardiovascular Diseases; DALY: Disability-Adjusted Life-Years; IHD: Ischemic Heart Disease; LDA: Latent Dirichlet Allocation; PCI: Percutaneous Coronary Intervention; QOL: Quality of Life; WOS: Web of Science

\section{Acknowledgments}

Not applicable.

\section{Authors' contributions}

BXT, CA, SN, CB, GHH, TTT, CAL, CSHH, RCMH conceived of the study, and participated in its design and implementation and wrote the manuscript. BXT, GHH, TाT analyzed the data. BXT, GHH, SN, CB, CAL, CSHH, RCMH helped to draft the manuscript. All authors read and approved the final manuscript.

\section{Funding}

No funding was received for this study.

\section{Availability of data and materials}

The datasets used and analyzed during the current study are available from the corresponding author on a reasonable request.

Ethics approval and consent to participate

Not applicable.

\section{Consent for publication}

Not applicable.

\section{Competing interests}

The authors declare that they have no competing interests.

\section{Author details}

${ }^{1}$ Department of Health Economics, Institute for Preventive Medicine and Public Health, Hanoi Medical University, No.1 Ton That Tung street, Dong Da, Hanoi, Vietnam. ${ }^{2}$ Bloomberg School of Public Health, Johns Hopkins University, Baltimore, MD, USA. ${ }^{3}$ Centre for Applied Health Economics (CAHE), Griffith University, Brisbane, Australia. ${ }^{4}$ Institute for Global Health Innovations, Duy Tan University, Da Nang, Vietnam. ${ }^{5}$ Center of Excellence in Evidence-based Medicine, Nguyen Tat Thanh University, Ho Chi Minh City, Vietnam. ${ }^{6}$ Center of Excellence in Behavioral Medicine, Nguyen Tat Thanh University, Ho Chi Minh City, Vietnam. ${ }^{7}$ Echo-lab, Vietnam National Heart Institute, Bach Mai Hospital, Hanoi, Vietnam. ${ }^{8}$ Department of Psychological Medicine, National University Hospital, Singapore, Singapore. ${ }^{9}$ Department of Psychological Medicine, Yong Loo Lin School of Medicine, National University of Singapore, Singapore, Singapore. ${ }^{10}$ Institute for Health Innovation and Technology (iHealthtech), National University of Singapore, Singapore, Singapore.

Received: 3 August 2019 Accepted: 22 July 2020

Published online: 29 July 2020

\section{References}

1. Global Health Data Exchange. GBD Results Tool. http://ghdx.healthdata.org/ gbd-results-tool. Accessed 18 May 2020.

2. Roth GA, Johnson C, Abajobir A, Abd-Allah F, Abera SF, Abyu G, et al. Global, regional, and National Burden of cardiovascular diseases for 10 causes, 1990 to 2015. J Am Coll Cardiol. 2017;70(1):1-25.

3. Heo S, Lennie TA, Okoli C, Moser DK. Quality of life in patients with heart failure: ask the patients. Heart Lung. 2009;38(2):100-8.

4. King RB. Quality of life after stroke. Stroke. 1996;27(9):1467-72.

5. Em S, Bozkurt M, Karakoc M, Caglayan M, Akdeniz D, Oktayoglu P, et al. Determining quality of life and associated factors in patients with stroke; 2015. p. $148-54$

6. Juenger J, Schellberg D, Kraemer S, Haunstetter A, Zugck C, Herzog W, et al. Health related quality of life in patients with congestive heart failure: comparison with other chronic diseases and relation to functional variables. Heart. 2002;87(3):235-41.

7. Opara JA, Jaracz K. Quality of life of post-stroke patients and their caregivers J Med Life. 2010;3(3):216-20,

8. Lewis EF, Johnson PA, Johnson W, Collins C, Griffin L, Stevenson LW. Preferences for quality of life or survival expressed by patients with heart failure. J Heart Lung Transplant. 2001;20(9):1016-24.

9. World Health Organization. WHOQOL: Measuring Quality of Life. https://www. who.int/healthinfo/survey/whoqol-qualityoflife/en/. Accessed 17 Apr 2020.

10. Baradaranfard F, Babaei S, Boroumand S, Mosleh S, Jafari F, Binaee N. The Relationship Between Quality of Life and Cardiovascular Self-Efficacy in Patients with Heart Failure: A Descriptive Correlation Study. Jundishapur J Chronic Dis Care. 2018;7(4):e68431. https://doi.org/10.5812/jjcdc.68431.

11. Alla F, Briancon S, Guillemin F, Juilliere Y, Mertes PM, Villemot JP, et al. Selfrating of quality of life provides additional prognostic information in heart failure. Insights into the EPICAL study. Eur J Heart Fail. 2002;4(3):337-43.

12. Konstam V, Salem D, Pouleur H, Kostis J, Gorkin L, Shumaker S, et al. Baseline quality of life as a predictor of mortality and hospitalization in 5,025 patients with congestive heart failure. SOLVD investigations. Studies of left ventricular dysfunction investigators. Am J Cardiol. 1996;78(8):890-5.

13. Darvishpour A, Javadi-Pashaki N, Salari A, Sadeghi T, Taleshan-Nejad M. Factors associated with quality of life in patients undergoing coronary angioplasty. Int J Health Sci (Qassim). 2017;11(4):35-41. 
14. Rezapoor PM, Shahriari MP, Sanei HM, Moeini MM. Effects of collaboration care model on the quality of life in patients after coronary angioplasty: a randomized controlled clinical trial. Int J Community Based Nurs Midwifery. 2017:5(2):112-22.

15. Ludt S, Wensing M, Szecsenyi J, van Lieshout J, Rochon J, Freund T, et al. Predictors of health-related quality of life in patients at risk for cardiovascular disease in European primary care. PLoS One. 2011;6(12): e29334.

16. Fatima K, Yousuf-Ul-Islam M, Ansari M, Bawany Fl, Khan MS, Khetpal A, et al. Comparison of the Postprocedural quality of life between coronary artery bypass graft surgery and percutaneous coronary intervention: a systematic review. Cardiol Res Pract. 2016;2016:7842514.

17. Groeneveld IF, Proper KI, van der Beek AJ, Hildebrandt VH, van Mechelen W. Lifestyle-focused interventions at the workplace to reduce the risk of cardiovascular disease-a systematic review. Scand J Work Environ Health. 2010;36:202-15.

18. Han E, Quek RYC, Tan SM, Singh SR, Shiraz F, Gea-Sánchez M, et al. The role of community-based nursing interventions in improving outcomes for individuals with cardiovascular disease: a systematic review. Int J Nurs Stud. 2019;100:103415

19. Widmer RJ, Collins NM, Collins CS, West CP, Lerman LO, Lerman A. Digital health interventions for the prevention of cardiovascular disease: a systematic review and meta-analysis. Mayo Clin Proc. 2015;90(4):469-80.

20. Martín-Martín A, Orduna-Malea E, Delgado L-CE. Coverage of highly-cited documents in Google scholar, web of science, and Scopus: a multidisciplinary comparison. Scientometrics. 2018;116(3):2175-88.

21. Clarivate Analytics. Web of Science databases. https://clarivate.com/ products/web-of-science/databases/. Accessed 26 June 2019.

22. World Health Organization. About cardiovascular diseases. https://www. who.int/cardiovascular_diseases/about_cvd/en/. Accessed 24 July 2019.

23. NCBI Mesh terms. Cardiovasc Dis Available from: https://www.ncbi.nlm.nih gov/mesh/?term=Cardiovascular+Diseases. Accessed 25 July 2019.

24. Wong CW, Kwok CS, Narain A, Gulati M, Mihalidou AS, Wu P, et al. Marital status and risk of cardiovascular diseases: a systematic review and metaanalysis. Heart. 2018;104(23):1937-48.

25. Alexander DD, Bylsma LC, Vargas AJ, Cohen SS, Doucette A, Mohamed M, et al. Dairy consumption and CVD: a systematic review and meta-analysis. $\mathrm{Br}$ J Nutr. 2016;115(4):737-50.

26. Li Y, Rapkin B, Atkinson TM, Schofield E, Bochner BH. Leveraging Latent Dirichlet Allocation in processing free-text personal goals among patients undergoing bladder cancer surgery. Qual Life Res. 2019;28(6):1441-55.

27. Valle D, Albuquerque P, Zhao Q, Barberan A, Fletcher RJ Jr. Extending the latent Dirichlet allocation model to presence/absence data: a case study on north American breeding birds and biogeographical shifts expected from climate change. Glob Chang Biol. 2018;24(11):5560-72.

28. Chen C, Zare A, Trinh HN, Omotara GO, Cobb JT, Lagaunne TA. Partial membership latent Dirichlet allocation for soft image segmentation. IEEE Trans Image Processing. 2017;26(12):5590-602.

29. Lu HM, Wei CP, Hsiao FY. Modeling healthcare data using multiple-channel latent Dirichlet allocation. J Biomed Inform. 2016;60:210-23.

30. Gross A, Murthy D. Modeling virtual organizations with latent Dirichlet allocation: a case for natural language processing. Neural Networks. 2014:58:38-49.

31. Michelson M, Reuter K. The significant cost of systematic reviews and metaanalyses: a call for greater involvement of machine learning to assess the promise of clinical trials. Contemporary Clin Trials Communications. 2019;16: 100443

32. Bornmann $L$, Leydesdorff $L$. Scientometrics in a changing research landscape: bibliometrics has become an integral part of research quality evaluation and has been changing the practice of research. EMBO Rep. 2014;15(12):1228-32

33. Quinn B. Pharmacological treatment of heart failure. Crit Care Nurs Q. 2007; 30:299-306

34. McKenzie DB, Cowley AJ. Drug therapy in chronic heart failure. Postgrad Med J. 2003;79(937):634-42.

35. Weisse AB. Cardiac surgery: a century of progress. Tex Heart Inst J. 2011; 38(5):486-90.

36. Warren TY, Barry V, Hooker SP, Sui X, Church TS, Blair SN. Sedentary behaviors increase risk of cardiovascular disease mortality in men. Med Sci Sports Exerc. 2010;42(5):879-85.
37. Buttar HS, Li T, Ravi N. Prevention of cardiovascular diseases: role of exercise, dietary interventions, obesity and smoking cessation. Exp Clin Cardiol. 2005; 10(4):229-49.

38. Yeh GY, Davis RB, Phillips RS. Use of complementary therapies in patients with cardiovascular disease. Am J Cardiol. 2006;98(5):673-80.

39. Grant SJ, Bin YS, Kiat H, Chang DH-T. The use of complementary and alternative medicine by people with cardiovascular disease: a systematic review. BMC Public Health. 2012;12(1):299.

40. Nabel EG, Plautz G, Nabel GJ. Site-specific gene expression in vivo by direct gene transfer into the arterial wall. Science. 1990;249(4974):1285-8.

41. Machaj F, Dembowska E, Rosik J, Szostak B, Mazurek-Mochol M, Pawlik A. New therapies for the treatment of heart failure: a summary of recent accomplishments. Ther Clin Risk Manag. 2019;15:147-55.

42. Rodgers $H$, Bosomworth $H$, Krebs HI, van Wijck F, Howel D, Wilson N, et al. Robot assisted training for the upper limb after stroke (RATULS): a multicentre randomised controlled trial. Lancet. 2019;394(10192):51-62.

43. Morone G, Paolucci S, Cherubini A, De Angelis D, Venturiero V, Coiro P, et al. Robot-assisted gait training for stroke patients: current state of the art and perspectives of robotics. Neuropsychiatr Dis Treat. 2017;13:1303-11.

44. De Hert M, Detraux J, Vancampfort D. The intriguing relationship between coronary heart disease and mental disorders. Dialogues Clin Neurosci. 2018; 20(1):31-40.

45. Kivimäki M, Kawachi I. Work stress as a risk factor for cardiovascular disease. Curr Cardiol Rep. 2015;17(9):74.

46. Falagas ME, Pitsouni El, Malietzis GA, Pappas G. Comparison of PubMed, Scopus, web of science, and Google scholar: strengths and weaknesses. FASEB J. 2008;22(2):338-42

47. AIRyalat SAS, Malkawi LW, Momani SM. Comparing Bibliometric analysis using PubMed, Scopus, and web of science databases. J Visualized Exp. 2019;(152):10.3791/58494.

48. Kokol P, Vošner HB. Discrepancies among Scopus, web of science, and PubMed coverage of funding information in medical journal articles. J Med Library Assoc. 2018;106(1):81-6.

\section{Publisher's Note}

Springer Nature remains neutral with regard to jurisdictional claims in published maps and institutional affiliations.
Ready to submit your research? Choose BMC and benefit from:

- fast, convenient online submission

- thorough peer review by experienced researchers in your field

- rapid publication on acceptance

- support for research data, including large and complex data types

- gold Open Access which fosters wider collaboration and increased citations

- maximum visibility for your research: over $100 \mathrm{M}$ website views per year

At $\mathrm{BMC}$, research is always in progress.

Learn more biomedcentral.com/submissions 